\title{
Chemoembolization with Drug-eluting Microspheres Loaded with Doxorubicin for the Treatment of Cholangiocarcinoma
}

\author{
CAMILLO ALIBERTI $^{2}$, RICCARDO CARANDINA ${ }^{2}$, DONATELLA SARTI ${ }^{1}$, ENRICO PIZZIRANI $^{2}$, \\ GAETANO RAMONDO ${ }^{2}$, LUCA MULAZZANI ${ }^{3}$, GIAN MARIA MATTIOLI ${ }^{3}$ and GIAMMARIA FIORENTINI ${ }^{1}$ \\ ${ }^{1}$ Oncology Unit, and ${ }^{3}$ Diagnostics for Images Unit and Interventional Radiology, \\ Agency Reunited Hospital of North Marche, Pesaro, Italy; \\ ${ }^{2}$ Oncology Radiodiagnostics, Oncology Institute of Veneto, \\ Institute for the Research and Treatment of Cancer (IRCC), Padua, Italy
}

\begin{abstract}
Aim: To report clinical outcomes of transarterial chemoembolization (TACE) using drug-eluting beads (DEBs) loaded with doxorubicin for the treatment of unresectable intrahepatic cholangiocarcinoma (CCA). Patients and Methods: We treated 127 patients with doxorubicin via TACE. Inclusion criteria were: diagnosis of unresectable CCA; indication for TACE, performance status (PS) 0-2, >3 months of life expectancy, $>18$ years old, written consent. TACE was performed using DEBs for 109 (86\%) patients and polythylene glycol drug-elutable microspheres (PEG) loaded with doxorubicin for 18 (14\%) patients. Results: Tumor response of the whole sample of 127 patients was partial response (PR) in 19 (15\%) patients, stable disease $(S D)$ in $101(80 \%)$ and progressive disease $(P D)$ in seven (5\%) 3 months after therapy, with no complete responses. There were differences between type of embolics: $P R$ was $7 \%$ and $77 \%, S D$ was $88 \%$ and $8 \%$, and $P D$ was $5 \%$ and $15 \%$, and the disease control rate was $95 \%$ and $85 \%$ in the DEB and PEG groups, respectively. Most frequent side-effects were: abdominal pain, fever, nausea, and transaminase rise. Conclusion: TACE was effective and safe for CCA treatment, with a high disease control rate. The best response of $P E G$ TACE was PR, whereas it was $S D$ for DEB-TACE.
\end{abstract}

This article is freely accessible online.

Correspondence to: Dr. Giammaria Fiorentini, U.O.C. Oncologia, Azienda Ospedaliera "Ospedali Riuniti Marche Nord", San Salvatore Hospital, Via Lombroso 1, 61122 Pesaro, Italy. Tel: +39 0721364124, Fax: +390721364094, e-mail: giammaria.fiorentini@ ospedalimarchenord.it

Key Words: Cholangiocarcinoma, chemoembolization, tumor response, safety, intra-arterial chemotherapy.
About $10 \%$ of primary hepatic cancer is represented by cholangiocarcinoma (CCA), with a preferential distribution among men rather than women (1). CCA classification includes intrahepatic, perihilar and distal extrahepatic cancer (galbladder or coledocus). These groups have different biological characteristics, clinical diagnoses, and treatment management (2).

Known risk factors for CCA include chronic inflammation, and injury of the bile tract, biliary lithiasis, and other novel risk factors such as obesity and hepatitis C virus infection (3). Over the past decades, CCA incidence and mortality has been increasing in Europe (4).

Surgery is considered the only curative option for CCA, however, it is possible only for $27-30 \%$ of patients (5). Unresectable CCA has a poor prognosis, with a median survival of 3-6 months $(6,7)$. Systemic chemotherapy aims to reduce tumor growth and symptoms, and to improve the quality of life of patients with unresectable CCA, however, its benefits are poor, leading to an overall survival of about 1 year $(8,9)$. The combination of systemic chemotherapy with capecitabine and intra-arterial administration of toxic drugs is increasingly being used (10-12).

Transarterial chemoembolization (TACE) allows the delivery of high concentration of chemotherapy selectively to the liver, in association with the embolization of the arteries afferent to the tumor (13-18). This method is achieving encouraging results in patients with CCA. Several studies with TACE for the therapy of unresectable CCA include mixed intrahepatic and extrahepatic CCA populations of only a small number of patients, for this reason it is difficult to have clear results on its efficacy. The purpose of this study was to report clinical outcomes of treatments of unresectable intrahepatic CCA with TACE using drug-eluting beads or polythylene glycol drug-eluting microspheres loaded with doxorubicin, in order to monitor tumor response, tolerability of the treatment, and patients' quality of life. 


\section{Materials and Methods}

Ethics. The protocol was approved by our Institutional Review Board, (approval no. 587) and the informed consent was signed by each enrolled patient. This research belongs to a study in the ClinicalTrials.gov registry (Identifier: NCT01920503)

Patients. We enrolled 127 consecutive patients with intrahepatic CCA from January 2000 to June 2016 at two Italian hospitals, when they met the following inclusion criteria: $>18$ years old, histological confirmation of unresectable intrahepatic CCA diagnosis; indication for locoregional therapy; Eastern Cooperative Oncology Group performance status (ECOG) $0-2$; tumor size evaluable with RECIST; life expectancy $\geq 3$ months.

Exclusion criteria included: contraindication to angiographic or visceral catheterization; extra-hepatic disease; inflammation; recurrent infection; peripheral neuropathy $\geq$ grade 2 ; pregnancy or breast feeding.

We registered the following data: metastases, previous therapies, disease stage, tumor dimension, carcinoembryonic antigen (CEA) and carbohydrate antigen (CA19.9) levels, tumor response, quality of life, performance status.

Transarterial chemoembolization. Rapid shrinkage of the tumor, decompression of biliary tree and partial response (PR) were the main purpose of TACE that was performed in patients with intrahepatic CCA with liver tumor size larger than the recommendations for local ablation or surgical approach. TACE was performed using DEBDOX or, from April 2015, polyethylene glycol drug-eluting microspheres (LIFDOX ${ }^{\circledR}$ ) loaded with doxorubicin. Before TACE, an interventional radiologist monitored the arterial perfusion of the lesions with a diagnostic angiography that included a selective celiac and superior mesenteric arteriograms. Extra-hepatic leakage blockade was performed using a distal catheter.

DEBDOX involved the use of Dc-Beads (BTG International Ltd, London, UK), LIFDOX ${ }^{\circledR}$ involved the use of polythylene glycol drug-elutable microspheres (Lifepearls ${ }^{\circledR}$, Terumo Europe NV, Leuven, Belgium). For both types of bead, the pearls were loaded with $100 \mu \mathrm{g}$ of doxorubicin, mixed with $5 \mathrm{ml}$ of non-ionic contrast solution and $5 \mathrm{ml}$ of distilled water, to guarantee correct volume of infusion. Dc-Beads required continuous agitation of the syringe to avoid bead deposition. LifePearls ${ }^{\circledR}$ are a new generation of loadable microspheres made of polyethylene glycol, a hydrophilic material which guarantees more compressibility, elasticity, and maximizes the time in suspension, thus improving catheter deliverability (15, 16). These microspheres were also more resilient to stress and attrition ( $<1 \%$ of damage during standard attrition testing).

Efficacy and tolerability. The National Cancer Institute Common Terminology Criteria for Adverse Events (NCI-CTCAE), version 4.0 was used to monitor the therapy tolerability (19).

Tumor response. RECIST1.1 was used to assess tumor response (20) from the abdominal and pelvic computed tomographic (CT) scan and magnetic resonance images. Clinical visits, laboratory testing for blood counts, liver functionality and tumor marker levels (carbohydrate antigen 19-9: CA19-9 and $\alpha$-fetoprotein) were also performed every 3 months after TACE, until disease progression or death.

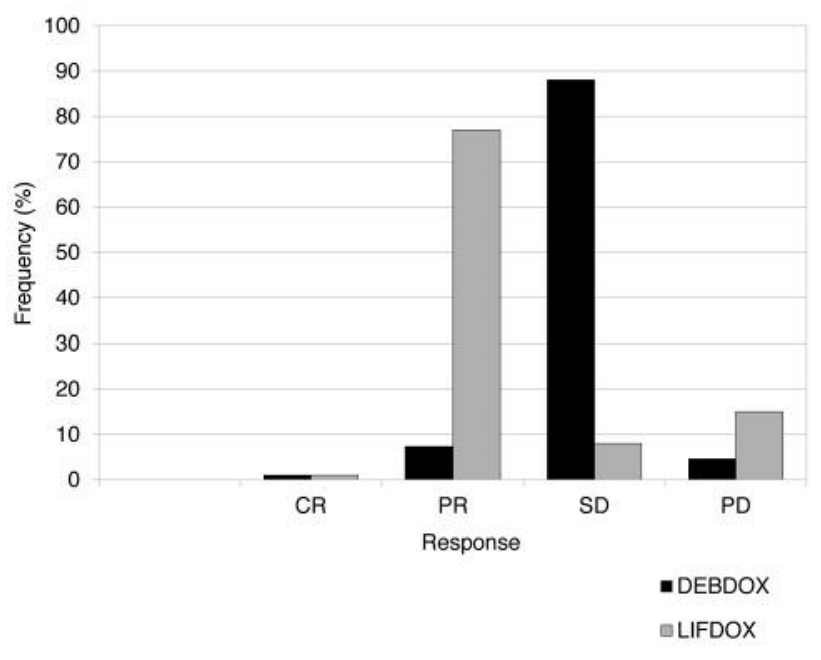

Figure 1. Tumor response after 3 months of therapy. CR: Complete response, PR: partial response, $S D$ : stable disease, PD: progressive disease.

Table I. Patient sample characteristics.

\begin{tabular}{lc}
\hline $\mathrm{N}=127$ & Value \\
\hline Male, n (\%) & $50(39)$ \\
Female, n (\%) & $77(61)$ \\
DEBDOX, n (\%) & $109(86)$ \\
LIFDOX, n (\%) & $18(14)$ \\
Median age (range), years & $66(43-83)$ \\
Median tumor size (range), mm & $54(20-140)$ \\
Median number of nodules (range) & $1(1-20)$ \\
Median CA19-9 (range), U/ml & $28.3(2-5590)$ \\
Median $\alpha$-fetoprotein (range), U/ml & $3.5(1-62.48)$ \\
Previous surgery, n (\%) & \\
$\quad$ No & $88(70)$ \\
Yes & $39(30)$ \\
\hline
\end{tabular}

Statistical analysis. Data of the whole sample $(\mathrm{N}=127)$ were analyzed with descriptive statistics, and continuous data are reported as median. Proportions are expressed in percentage. Chi-square and Student's $t$-test, were used to assess significance of continuous variables $(p<0.05)$. The Kaplan-Meier curve was used for survival analysis.

\section{Results}

The sample. We enrolled 127 patients, 109 (39\%) treated with the DEBDOX method, and $18(6 \%)$ with the LIFDOX $^{\circledR}$ (Table I). The median age was 66 (range=43-83) years. Of these patients, $50(39 \%)$ were males and 77 (61\%) females, $39(30 \%)$ had undergone previous surgery (Table I). They all 

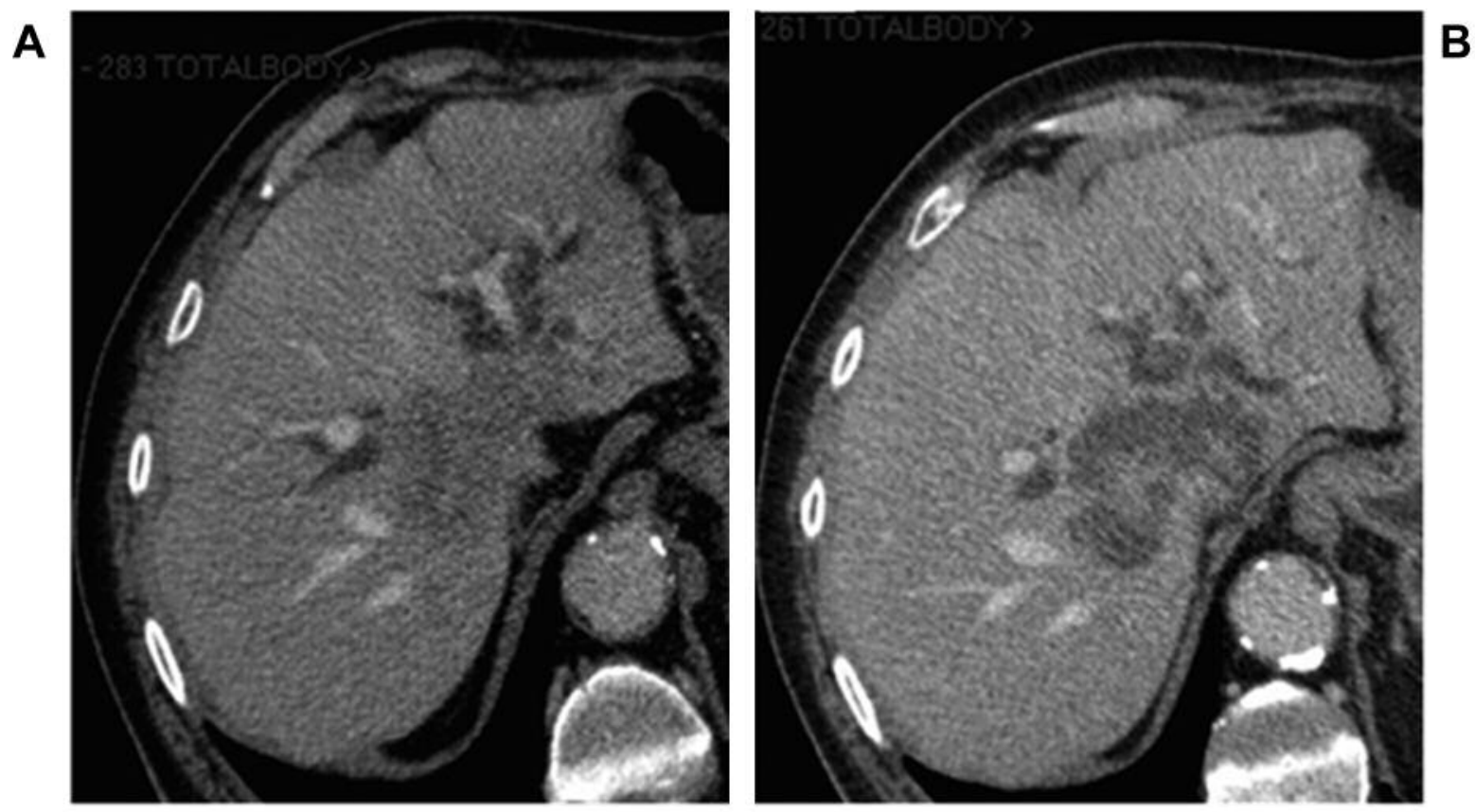

Figure 2. Effects of transarterial chemoembolization (TACE) on intrahepatic cholangiocarcinoma before (A) and 3 months after (B) TACE.

received first-line chemotherapy, and $43(55 \%)$ of them also received second-line chemotherapy.

Tumor response. Tumor response of the whole sample of 127 patients was partial response (PR) in $19(15 \%)$ patients, stable disease (SD) in $101(80 \%)$ patients, and progressive disease (PD) in seven (5\%) patients at 3 months after therapy. Complete response was not observed. The disease control rate was 95\% and 85\% in the DEB and PEG groups, respectively.

There were differences according to the type of embolic used: PR was $7 \%$ in DEBDOX and $77 \%$ in LIFDOX $^{\circledR}$ group. SD was $88 \%$ in the DEBDOX and $8 \%$ in LIFDOX $^{\circledR}$ group. PD was $5 \%$ in DEBDOX and $15 \%$ in LIFDOX $^{\circledR}$ group (Figure 1). Four patients were able to undergo resection (3.8\% downsizing) after DEBDOX treatment. Effects of TACE on tumor are reported in Figure 2.

Overall survival. Median follow-up time was 14.3 months (range $=1-26$ months) for the DEBDOX group, and 13 (range $=1-15$ ) months for the LIFDOX group. At this median follow-up, 71 patients were alive $(65 \%)$ and $38(35 \%)$ had died in the DEBDOX group. The median OS of the LIFDOX group was 14.53 (95\% confidence interval=9.17-15.23) months. Data on overall survival for the LIFDOX group were only preliminary because this method was only recently introduced.
Tolerability. Adverse events were mainly of grade 2 intensity. The most frequent side-effects of TACE were: abdominal pain ( $37 \%$ for DEBDOX, and $42 \%$ for LIFDOX $^{\circledR}$ ), fever ( $87 \%$ for DEBDOX, and $35 \%$ for LIFDOX ${ }^{\circledR}$ ), nausea $(48 \%$ for DEBDOX, and $42 \%$ for LIFDOX ${ }^{\circledR}$ ), and transaminase rise $\left(82 \%\right.$ for DEBDOX, and $21 \%$ for LIFDOX $\left.^{\circledR}\right)$.

Adverse events of grade 3 intensity were nausea/vomiting (24\%) for the DEBDOX group, and fever (7\%) and pain (7\%) for the LIFDOX group. No adverse event of grade 4 intensity was observed.

\section{Discussion}

Surgical resection of CCA is possible only in $27-30 \%$ of cases, due to extensive dimensions or tumor invasion of blood vessels (5). Non-surgical methods include systemic therapies with 5-fluorouracil, doxorubicin, cisplatin and mitomycin C (response rate of about 10-30\%), combinations with gemcitabine or local radiotherapy (median survival=512 months), however, their benefit is very limited, a better result in survival is obtained with intra-arterial therapies $(8$, $9,13)$.

Target methods, aiming to direct the treatment locally inside the tumor, are valid alternatives to systemic chemotherapy for unresectable CCA, including thermal ablation with radiofrequency ablation or microwave ablation, and chemoembolization (21-23). 
The most encouraging results for the therapy of unresectable CCA are obtained with TACE, which allows the combined selective infusion of toxic drug to the embolization of feeding blood vessels of the lesion, resulting in longer survival for patients with liver carcinoma and CCA $(10,14$, 15). TACE can be performed using several drugs, such as gemcitabine, mitomycin $\mathrm{C}$ and doxorubicin $(23,24)$.

Improvements of TACE technique include the use of new embolics that bind drug molecules through reversible electrochemical bonds, and at the same time produce a selctive arterial embolization, such as DC microspheres, and more recently the polythylene glycol drug-elutable microspheres $(15,16)$. These embolics allow the slow release of drug directly inside the tumor, reducing blood dispersion, and resulting in greater necrosis and toxicity reduction (24).

Although CCA is very different from hepatocellular carcinomas, because of the type of vascularization, large tumor dimensions and sensitivity to toxic drug, TACE is used also in CCA with promising results, suggesting its feasibility for intrahepatic CCA. Published data, however, include only small number of patients and for this reason clinicians are still skeptical on its efficacy for CCA therapy.

For this reason, we collected the data from a lager sample, including 127 patients with unresectable intrahepatic CCA, who were treated with TACE and doxorubicin. The purpose of this study was to report clinical outcomes of TACE using drug-eluting beads (DEBDOX) or polythylene glycol drugeluting microspheres $\left(\right.$ LIFDOX $\left.^{\circledR}\right)$, both loaded with doxorubicin, for the treatment of unresectable CCA. In this report, we present the clinical outcomes of this treatment.

Although tumor response differed between type of embolic used the data were comparable to previous results $(25,26)$, which showed PR in $25.5 \%$ patients, while $61.5 \%$ had SD and $13.0 \%$ had PD, with a median OS of 13.2 months (26).

The tolerability profile was in agreement with previous studies, reporting grade 3 toxicities and no grade $4(14,15)$.

Data on overall survival for patients treated with LIFDOX $^{\circledR}$ were only preliminary because this method was recently introduced, and our subset of patients was limited. Our results for survival of this group (median of 14.53 months) were comparable with the median survival of 11.2 months for patients treated with TACE reported by Park and colleagues and $72 \%$ of survival at 12 months after TACE reported in another study (25-27).

Time to progression was 3.25 (95\% confidence interval=3.1-11.2) months and overall time to progression was $13.50(95 \%$ confidence interval=5.9-14.2) months for the LIFDOX $^{\circledR}$ group, similar results were reported by other studies $(14,18)$.

These data suggest that a therapy for intrahepatic CCA is necessary, although the sequence or the best treatment option are unknown. Future studies are required to assess the efficacy of local radiofrequency or microwave ablation, locoregional treatment or TACE, and verify which treatment option is better than the others and in which cases one method should be preferred rather than another.

In conclusion, our results suggest that DEBDOX and LIFDOX $^{\circledR}$ were effective and safe in TACE. Response to LIFDOX $^{\circledR}$, however, was mainly PR, whereas DEBDOX induced a higher percentage of cases of SD. LIFDOX ${ }^{\circledR}$ might be able to improve the outcome in this setting but further studies are required to confirm these results.

\section{Disclosure}

All Authors declare no conflict of interest exists in regard to this study.

\section{References}

1 Shaib $Y$ and El-Serag HB: The epidemiology of cholangiocarcinoma. Semin Liver Dis 24: 115-125, 2004.

2 Ghouri YA, Mian I and Blechacz B: Cancer review: Cholangiocarcinoma. J Carcinog 14: 1, 2005.

3 Bragazzi MC, Cardinale V, Carpino G, Venere R, Semeraro R, Gentile R, Gaudio E and Alvaro D: Cholangiocarcinoma: Epidemiology and risk factors. Transl Gastrointest Cancer 1: 2132, 2012.

4 Bertuccio P, Bosetti C, Levi F, Decarli A, Negri E and La Vecchia C: A comparison of trends in mortality from primary liver cancer and intrahepatic cholangiocarcinoma in Europe. Ann Oncol 24(6): 1667-1674, 2013.

5 Tan JC, Coburn NG, Baxter NN, Kiss A and Law CH: Surgical management of intrahepatic cholangiocarcinoma--a populationbased study. Ann Surg Oncol 15(2): 600-608, 2008.

6 Tazici C, Niemeyer DJ, Iannitti DA and Russo MW: Hepatocellular carcinoma and cholangiocarcinoma: an update. Expert Rev Gastroenterol Hepatol 8(1): 63-82, 2014.

7 Tamandl D, Herberger B, Gruenberger B, Puhalla H, Klinger M and Gruenberger T: Influence of hepatic resection margin on recurrence and survival in intrahepatic cholangiocarcinoma. Ann Surg Oncol 15: 2787-2794, 2008.

8 Brito AF, Abrantes AM, Encarnação JC, Tralhão JG and Botelho MF: Cholangiocarcinoma: from molecular biology to treatment. Med Oncol 32(11): 245, 2015.

9 Valle J, Wasan H, Palmer DH, Cunningham D, Anthoney A, Maraveyas A, Madhusudan S, Iveson T, Hughes S, Pereira SP, Roughton M, Bridgewater $\mathrm{J}$; ABC-02 Trial Investigators: Cisplatin plus gemcitabine versus gemcitabine for biliary tract cancer. The New Engl J Med 362(14): 1273-1281, 2010.

10 Cantore M, Mambrini A, Fiorentini G, Rabbi C, Zamagni D, Caudana R, Pennucci C, Sanguinetti F, Lombardi M and Nicoli $\mathrm{N}$ : Phase II study of hepatic intraarterial epirubicin and cisplatin, with systemic 5-fluorouracil in patients with unresectable biliary tract tumors. Cancer 103(7): 1402-1407, 2005.

11 Seidensticker R, Seidensticker M, Doegen K, Mohnike K, Schütte K, Stübs P, Kettner E, Pech M, Amthauer H and Ricke $\mathrm{J}$ : Extensive use of interventional therapies improves survival in unresectable or recurrent intrahepatic cholangiocarcinoma. Gastroenterol Res Pract 2016: 8732521, 2016. 
12 Aliberti C, Benea G, Tilli M and Fiorentini G: Chemoembolization (TACE) of unresectable intrahepatic cholangiocarcinoma with slow-release doxorubicin-eluting beads: preliminary results. Cardiovasc Intervent Radiol 31: 883-888, 2008.

13 Park SY, Kim JH, Yoon HJ, Lee IS, Yoon HK and Kim KP: Transarterial chemoembolization versus supportive therapy in the palliative treatment of unresectable intrahepatic cholangiocarcinoma. Clin Radiol 66(4): 322-328, 2011.

14 Kiefer MV, Albert M, McNally M, Robertson M, Sun W, Fraker D, Olthoff K, Christians K, Pappas S, Rilling W and Soulen MC: Chemoembolization of intrahepatic cholangiocarcinoma with cisplatinum, doxorubicin, mitomycin $\mathrm{C}$, ethiodol, and polyvinyl alcohol: a 2-center study. Cancer 117(7): 1498-1505, 2011.

15 Gusani NJ, Balaa FK, Steel JL, Geller DA, Marsh JW, Zajko AB, Carr BI and Gamblin TC: Treatment of unresectable cholangiocarcinoma with gemcitabine-based transcatheter arterial chemoembolization (TACE): a single-institution experience. J Gastrointest Surg 12: 129-137, 2008.

16 Aliberti C, Carandina R, Sarti D, Mulazzani L, Catalano V, Felicioli A, Coschiera P and Fiorentini G: Hepatic arterial infusion of polyethylene glycol drug-eluting beads for primary and metastatic liver cancer therapy. Anticancer Res 36: 35153521, 2016.

17 Venturini M, Sallemi C, Agostini G, Marra P, Cereda S, Reni M, Aldrighetti L, De Cobelli F, Del Maschio A: Chemoembolization with drug-eluting beads preloaded with irinotecan (DEBIRI) $v s$. doxorubicin (DEBDOX) as a second-line treatment for liver metastases from cholangiocarcinoma: a preliminary study. Br J Radiol 89(1067): 20160247, 2016.

18 Kuhlmann JB, Euringer W, Spangenberg HC, Breidert M, Blum HE, Harder $J$ and Fischer R: Treatment of unresectable cholangiocarcinoma: conventional transarterial chemoembolization compared with drug-eluting bead-transarterial chemoembolization and systemic chemotherapy. Eur J Gastroenterol Hepatol 24(4): 437-443, 2012.

19 Therasse P, Arbuck SG, Eisenhauer EA, Wanders J, Kaplan RS, Rubinstein L, Verweij J, Van Glabbeke M, van Oosterom AT and Christian MC: New guidelines to evaluate the response to treatment in solid tumors. European Organization for Research and Treatment of Cancer, National Cancer Institute of the United States, National Cancer Institute of Canada. J Natl Cancer Inst 92(3): 205-216, 2000.
20 Therasse P, Eisenhauer EA and Verweij J: RECIST revisited: a review of validation studies on tumour assessment. Eur J Cancer 42(8): 1031-1039, 2006.

$21 \mathrm{Xu}$ HX, Wang Y, Lu MD and Liu LN: Percutaneous ultrasoundguided thermal ablation for intrahepatic cholangiocarcinoma. $\mathrm{Br}$ J Radiol 85(1016): 1078-1084, 2012.

22 Li J, Wang Q, Lei Z, Wu D, Si A, Wang K, Wan X, Wang Y, Yan Z, Xia Y, Lau WY, Wu M and Shen F: Adjuvant transarterial chemoembolization following liver resection for intrahepatic cholangiocarcinoma based on survival risk stratification. Oncologist 20(6): 640-647, 2015.

23 Kim JH, Yoon HK, Sung KB, Ko GY, Gwon DI, Shin JH and Song HY: Transcatheter arterial chemoembolization or chemoinfusion for unresectable intrahepatic cholangiocarcinoma: clinical efficacy and factors influencing outcomes. Cancer 113(7): 1614-1622, 2008.

24 Burger I1, Hong K, Schulick R, Georgiades C, Thuluvath P, Choti M, Kamel I and Geschwind JF: Transcatheter arterial chemoembolization in unresectable cholangiocarcinoma: initial experience in a single institution. J Vasc Interv Radiol 16(3): 353-361, 2005.

25 Eltawil KM, Berry R, Abdolell M and Molinari M: Quality of life and survival analysis of patients undergoing transarterial chemoembolization for primary hepatic malignancies: a prospective cohort study. HPB 14(5): 341-350, 2012.

26 Kuhlmann JB and Blum HE: Locoregional therapy for cholangiocarcinoma. Curr Opin Gastroenterol 29(3): 324-328, 2013.

27 Hyder O, Marsh JW, Salem R, Petre EN, Kalva S, Liapi E, Cosgrove D, Neal D, Kamel I, Zhu AX, Sofocleous CT, Geschwind JF and Pawlik TM: Intra-arterial therapy for advanced intrahepatic cholangiocarcinoma: a multi-institutional analysis. Ann Surg Oncol 20(12): 3779-3786, 2013.

Received February 23, 2017

Revised February 27, 2017 Accepted March 2, 2017 